\title{
Rehydrated sterically stabilized phospholipid nanomicelles of budesonide for nebulization: physicochemical characterization and in vitro, in vivo evaluations
}

\author{
This article was published in the following Dove Press journal: \\ International Journal of Nanomedicine \\ 13 October 2011 \\ Number of times this article has been viewed
}

\section{Mohanad Naji Sahib \\ Yusrida Darwis \\ Kok Khiang Peh \\ Shaymaa Abdalwahed \\ Abdulameer \\ Yvonne Tze Fung Tan}

School of Pharmaceutical Sciences, Universiti Sains Malaysia, Penang, Malaysia
Correspondence: Mohanad Naji Sahib School of Pharmaceutical Sciences, Universiti Sains Malaysia, I 1800 Minden, Penang, Malaysia

Tel +60164897348

Fax +6046570017

Email mohanad_pharm@yahoo.com
Background: Inhaled corticosteroids provide unique systems for local treatment of asthma or chronic obstructive pulmonary disease. However, the use of poorly soluble drugs for nebulization has been inadequate, and many patients rely on large doses to achieve optimal control of their disease. Theoretically, nanotechnology with a sustained-release formulation may provide a favorable therapeutic index. The aim of this study was to determine the feasibility of using sterically stabilized phospholipid nanomicelles of budesonide for pulmonary delivery via nebulization.

Methods: PEG $_{5000}$-DSPE polymeric micelles containing budesonide (BUD-SSMs) were prepared by the coprecipitation and reconstitution method, and the physicochemical and pharmacodynamic characteristics of BUD-SSMs were investigated.

Results: The optimal concentration of solubilized budesonide at $5 \mathrm{mM} \mathrm{PEG}_{5000}$-DSPE was $605.71 \pm 6.38 \mu \mathrm{g} / \mathrm{mL}$, with a single-sized peak population determined by photon correlation spectroscopy and a particle size distribution of $21.51 \pm 1.5 \mathrm{~nm}$. The zeta potential of BUD-SSMs was $-28.43 \pm 1.98 \mathrm{mV}$. The percent entrapment efficiency, percent yield, and percent drug loading of the lyophilized formulations were $100.13 \% \pm 1.09 \%, 97.98 \% \pm 1.95 \%$, and $2.01 \% \pm 0.02 \%$, respectively. Budesonide was found to be amorphous by differential scanning calorimetry, and had no chemical interaction with PEGylated polymer according to Fourier transform infrared spectroscopy. Transmission electron microscopic images of BUD-SSMs revealed spherical nanoparticles. BUD-SSMs exhibited prolonged dissolution behavior compared with Pulmicort $\operatorname{Respules}^{\circledR}(P<0.05)$. Aerodynamic characteristics indicated significantly higher deposition in the lungs compared with Pulmicort Respules ${ }^{\circledR}$. The mass median aerodynamic, geometric standard deviation, percent emitted dose, and the fine particle fraction were $2.83 \pm 0.08 \mu \mathrm{m}, 2.33 \pm 0.04 \mu \mathrm{m}$, $59.13 \% \pm 0.19 \%$, and $52.31 \% \pm 0.25 \%$, respectively. Intratracheal administration of BUD-SSMs 23 hours before challenge $(1 \mathrm{mg} / \mathrm{kg})$ in an asthmatic/chronic obstructive pulmonary disease rat model led to a significant reduction in inflammatory cell counts $(76.94 \pm 5.11)$ in bronchoalveolar lavage fluid compared with administration of Pulmicort Respules ${ }^{\circledR}(25.06 \pm 6.91)$.

Conclusion: The BUD-SSMs system might be advantageous for asthma or chronic obstructive pulmonary disease and other inflammatory airway diseases.

Keywords: micelles, PEGylated polymer, aerodynamics, pharmacodynamics

\section{Introduction}

Asthma, chronic obstructive pulmonary disease, and other pulmonary diseases can be efficiently treated via the pulmonary route if high and prolonged drug concentrations are maintained in the lungs. ${ }^{1,2}$ Local treatment of lung disorders via pulmonary drug 
delivery offers many advantages over oral or intravenous routes of administration, because direct deposition of drug at the diseased site could increase local drug concentrations, improve the pulmonary receptor occupancy, and reduce the overall dose required and the side effects that result from high doses of drug. ${ }^{3}$ In addition, sustained-release formulations for pulmonary delivery may result in a favorable therapeutic index by prolonging drug action at the target site, reducing its side effects, and enhancing patient compliance. ${ }^{4}$

Microparticle and nanoparticle drug carrier systems have been extensively studied. ${ }^{3,5-8}$ However, the majority of these formulations have not successfully controlled the inhaled therapeutics in the pulmonary system for more than a few hours due to efficient clearance of the therapeutics from the deep lung either through phagocytosis or via the rapid absorption of the delivered therapeutics by the alveoli, making them more suitable for enhancing systemic bioavailability. ${ }^{4,9}$ Controlling the drug in the respiratory tract may be achievable by employing suitable carrier systems with appropriate drug-release characteristics. Among these drug carrier systems, polymeric micelles are particularly promising and are receiving increasing attention. ${ }^{10,11}$ So-called polymeric micelle colloidal dispersions are self-assembled core-shell nanostructures formed in an aqueous solution consisting of hydrophobic fragments of amphiphilic molecules forming the core of a micelle, which is segregated from the environment by hydrophilic parts of the molecules that form the micelle corona. ${ }^{12,13}$ The cargo space (core) formed from the hydrophobic segment solubilizes a variety of poorly soluble therapeutic and diagnostic agents. This solubilization increases the bioavailability and circulation time after parenteral administration, as well as modifying the pharmacokinetics and biodistribution of the therapeutic agents. ${ }^{14,15}$ The small size of the micelles permits their extravasation and accumulation in a variety of pathological sites such as tumors. ${ }^{16}$ Additionally, polymeric micelles are easily prepared on a large scale. ${ }^{14}$

A variety of block copolymers may be used to form polymeric micelles, including conjugates of polyethylene glycol and phosphatidylethanolamine (PEG-DSPE), to form so-called sterically stabilized phospholipid nanomicelles (SSMs). ${ }^{17}$ Polymeric micelles have the ability to prolong the circulation time (in vivo experiments) and the ability to accumulate in target organs. ${ }^{18}$ In addition, the fact that humans secrete phospholipase A2, which is able to degrade PEG-DSPE, makes them biodegradable. ${ }^{19}$

However, to date, no in vitro or in vivo study of the efficiency of sterically stabilized phospholipid nanomicelles containing a poorly water-soluble corticosteroid drug (budesonide) as a pulmonary delivery system has been reported. Therefore, this study focused on the formulation, characterization, and in vitro and in vivo evaluation of sterically stabilized phospholipid nanomicelles containing budesonide as a pulmonary delivery system via nebulization.

\section{Materials and methods Materials}

1,2-Distearoyl-sn-glycero-3-phosphoethanolamine-Nmethoxy-poly(ethylene glycol 5000) ( $\mathrm{PEG}_{5000}$-DSPE) was purchased from NOF Corporation (Tokyo, Japan) and budesonide (molecular weight $430.50 \mathrm{~g} / \mathrm{mol}$ ) was purchased from Symbiotica Specialty Ingredients Sdn Bhd (Kedah, Malaysia). High-pressure liquid chromatography (HPLC)-grade methanol and chloroform were purchased from Fisher Scientific (Franklin Lakes, NJ, and Leicestershire, UK, respectively). Phosphate-buffered saline tablets were purchased from Sigma-Aldrich Chemie Gmbh (Steinheim, Germany).

\section{Preparation of BUD-SSMs}

Aqueous dispersions of BUD-SSMs were prepared by the coprecipitation and reconstitution method using some modifications, as previously reported..$^{20}$ Known amounts of budesonide and $\mathrm{PEG}_{5000}$-DSPE were mixed at different molar ratios. The mixtures were subsequently sonicated for 2 minutes using a sonicator processor (Bransonic Ultrasonic 8510, Danbury, CT). The content was transferred to a $50 \mathrm{~mL}$ round-bottomed flask, mixed, and vortexed for one minute. The organic solvents were evaporated under vacuum at $40^{\circ} \mathrm{C}$ using a rotary evaporator (Eyela N-1001S-W, Tokyo, Japan). Any traces of remaining solvent in the film obtained were removed under vacuum overnight. ${ }^{21}$ The dried films were rehydrated with phosphatebuffered saline, and the SSMs were formed by shaking at $40^{\circ} \mathrm{C}$ for 10 minutes. Drug that was not encapsulated was separated by filtration of the micellar solutions using a $0.2 \mu \mathrm{m}$ Minisart microfilter (Sartorius, Germany). The maximum solubility of budesonide in the SSMs was determined by keeping the $\mathrm{PEG}_{5000}$-DSPE concentration fixed $(5 \mathrm{mM})$ and changing the drug concentration (budesonide to $\mathrm{PEG}_{5000}$-DSPE molar ratios ranged from 0.20 to 0.34 ) until a homogeneous system was confirmed by photon correlation spectroscopy as a singlesize peak population using a Zetasizer (Malvern 1000HSA, Worcestershire, UK). The amount of solubilized budesonide in the SSMs was determined spectrophotometrically using an ultraviolet spectrophotometer (Hitachi, model U-2000, Japan) at $244 \mathrm{~nm}$ after diluting the clear aqueous dispersion with methanol (drug-SSMs:methanol, 1:3 [v/v]). BUD-SSMs with the maximum solubility of budesonide were lyophilized 
(Labconco 7753501, Labconco Corporation, Kansas City, MO) to form a lyophilized cake ready for reconstitution.

\section{Physicochemical characterization of BUD-SSMs}

The following parameters of the BUD-SSM formulations were characterized: particle size, using a Zetasizer (Malvern 1000HSA); zeta potential, using a Zeecom zeta potential analyzer (Symphotic TII Corporation, Camarillo, CA); and entrapment efficiency $(\% \mathrm{EE})$, yield percentage $(\% \mathrm{Y})$, and drug loading percentage $(\% \mathrm{DL})$ using the following equations according to a previously published method: ${ }^{22}$

$$
\% E E=\left(\frac{a}{b}\right) \times 100 \%
$$

where $(a)$ is the concentration of drug loaded in SSMs $(\mu \mathrm{g} / \mathrm{mL})$ and $(b)$ is the amount of drug used in SSMs preparation $(\mu \mathrm{g} / \mathrm{mL})$ :

$$
\% Y=\left(\frac{\text { Weight of the nanoparticles }}{\text { Weight of the feeding polymer and drug }}\right) \times 100 \%
$$

$$
\% D L=\left(\frac{\text { Weight of the drug in nanoparticles }}{\text { Weight of the nanoparticles }}\right) \times 100 \%
$$

We also performed Fourier transform infrared spectroscopy using an infrared spectrophotometer (Thermo Nicolet Corporation, Nexus model, Madison, WI), equipped with OMNIC 6.1 version software, differential scanning calorimetry (Perkin Elmer, Pyris 6, Boston, MA), and morphological examinations of the rehydrated BUD-SSMs using a transmission electron microscope (Phillips CM12, Eindhoven, The Netherlands) with Docu version 3.2 image analysis.

\section{Solubility and dissolution study}

To determine the sink condition, the solubility of budesonide in phosphate-buffered saline was measured by placing an excess amount of budesonide (300 mg) into $5 \mathrm{~mL}$ of phosphate-buffered saline ( $\mathrm{pH} 7.4$ ) in a dialysis bag (Spectra/pro, molecular weight cutoff $10,000 \mathrm{kD}$, Spectrum, Torrance, CA) placed in a $100 \mathrm{~mL}$ phosphate-buffered saline Pyrex bottle and shaken horizontally at $100 \mathrm{rpm}$ in a thermostatic water bath (Memmrete WB22, Germany) at $37^{\circ} \mathrm{C} \pm 0.5^{\circ} \mathrm{C}$. Samples of the drug solution were withdrawn from the bottle $(200 \mu \mathrm{L}$, after 30 hours) and analyzed by a validated HPLC method, as previously described. ${ }^{23}$ The resulting equilibrium drug concentration was used to calculate the saturated solubility drug concentration. ${ }^{24}$
For the dissolution study, rehydrated BUD-SSMs or Pulmicort Respules ${ }^{\circledR}$ (containing the equivalent amount of budesonide [400 $\mu \mathrm{g}$ ] required for the sink condition) were diluted in $5 \mathrm{~mL}$ of phosphate-buffered saline (pH 7.4) and transferred into a dialysis bag. The two ends of the dialysis bag were fastened securely with special clips spaced $5 \mathrm{~cm}$ apart. The dialysis bag was placed into a Pyrex screw-capped bottle containing $100 \mathrm{~mL}$ of phosphate-buffered saline ( $\mathrm{pH}$ 7.4) as the dissolution medium and $0.02 \%$ of sodium azide (SigmaAldrich Chemie Gmbh) to prevent microbial growth. The bottle was shaken horizontally at $100 \mathrm{rpm}$ in a thermostatic water bath (Memmrete WB22, Germany) at $37^{\circ} \mathrm{C} \pm 0.5^{\circ} \mathrm{C}$. At predetermined time intervals, $200 \mu \mathrm{L}$ samples were withdrawn from the bottle and analyzed by a validated HPLC method, as described previously. ${ }^{23}$ Briefly, the system consisted of a Shimadzu LC-20AD delivery pump (Shimadzu, Tokyo, Japan) equipped with a SIL-20A HT prominence autosampler (Shimadzu) fitted with a $100 \mu \mathrm{L}$ sample loop, an ultraviolet-visible detector (SPD-20A, Shimadzu), a DGU-20A3 prominence degasser (Shimadzu), and a chromato-integrator (CBM-20A prominence Communications Bus Model, Shimadzu). The chromatographic separation of the analyte was performed at $40^{\circ} \mathrm{C}$ (CTO-10AS VP, Shimadzu column oven) using a Zorbax Eclipse Plus $(250 \times 4.6 \mathrm{~mm}, 5 \mathrm{~mm})$ analytical column connected to a SecurityGuard ${ }^{\mathrm{TM}}$ cartridge system (Zorbax, Agilent Technologies, Colorado Springs, CO). The mobile phase consisted of $10 \mathrm{mM}$ ammonium acetate $(\mathrm{pH} 5$, adjusted with orthophosphoric acid) to acetonitrile (37:63). The mobile phase was filtered through a $0.45 \mu \mathrm{m}$ nylon membrane filter (Whatman, Maidstone, UK) under vacuum and degassed prior to use. The analysis was conducted at a flow rate of $1.0 \mathrm{~mL} /$ minute at an ultraviolet detection wavelength of $254 \mathrm{~nm}$. The injection volume was $50 \mu \mathrm{L}$.

The kinetics of drug release were examined using the previously described add-in DDSolver program. ${ }^{25}$ Different mathematical kinetic models (zero-order, first order, Higuchi, Hixson-Crowell, and Baker-Lonsdale) were used to determine the drug release kinetics. The criteria for selecting the most appropriate model were based on the goodness of fit (adjusted coefficient of determination, $\mathrm{R}^{2}$ adjusted) and the Akaike information criterion. ${ }^{26}$

\section{Aerodynamic characterization}

In vitro deposition was investigated using a next generation impactor (Model 170) connected to a vacuum pump (HCP4) and Pari LC nebulizer (Pari LC plus nebulizer connected to an airjet compressor Pari Master type 84G73, Munich, Germany). A flow meter (DFM2) (Copley Scientific, UK) was used to 
calibrate the airflow through the next generation impactor. Two $\mathrm{mL}$ of an aqueous preparation containing $0.5 \mathrm{mg}$ of rehydrated BUD-SSMs was nebulized for 15 minutes at a room temperature of $28^{\circ} \mathrm{C}$ and a relative humidity of $65 \%$. The effective cutoff diameters for the impactor at a flow rate of $60 \mathrm{~L} / \mathrm{min}$ were: $8.06 \mu \mathrm{m}$ (stage 1), $4.46 \mu \mathrm{m}$ (stage 2), $2.82 \mu \mathrm{m}$ (stage 3), $1.66 \mu \mathrm{m}$ (stage 4), $0.94 \mu \mathrm{m}$ (stage 5), $0.55 \mu \mathrm{m}$ (stage 6), and $0.34 \mu \mathrm{m}$ (stage 7 ). The flow rate of $60 \mathrm{~L} /$ minute simulated the mean peak inspiratory flow rate of adult asthmatic patients. ${ }^{27}$ Each stage of the next generation impactor, the induction port, and the inhaler device were rinsed with $10 \mathrm{~mL}$ of the respective HPLC mobile phase and collected for quantitative analysis by HPLC. ${ }^{23}$

The mass median aerodynamic diameter and geometric standard deviation were calculated after plotting the cumulative amount of drug under size deposited in each stage of the cascade impactor versus their corresponding aerodynamic diameter as specified by the cascade impactor using logprobability paper. ${ }^{28}$ On this graph, the mass median aerodynamic diameter of the aerosolized particles is the particle size at which the line crosses the 50\% mark (mass median aerodynamic diameter $[\mu \mathrm{m}]=\mathrm{D}_{50 \%}$ ).

From a log-normal distribution that is normal with respect to aerodynamic diameter, ${ }^{28}$ the geometric standard deviation (GSD) becomes:

$$
G S D=\sqrt{\left(\frac{84.1 \% \text { undersize }}{15.9 \% \text { undersize }}\right)}
$$

The emitted dose (ED) was determined as the percentage of total amount of drug available for nebulization: ${ }^{23,27}$

$$
\begin{aligned}
E D= & \left(\frac{\text { Amount of drug recovered in the cascade impactor }}{\text { Amount of drug initially loaded in the device }}\right) \\
& \times 100 \%
\end{aligned}
$$

The fine particle fraction was calculated as the total amount of drug deposited on Stage 2 or 3 to filter:23,27,29

$$
\begin{aligned}
F P F= & \left(\frac{\text { Amount of drug recovered from stage } 2 \text { or } 3 \text { to filter }}{\text { Amount of drug initially loaded in the device }}\right) \\
& \times 100 \%
\end{aligned}
$$

\section{Inhibitory duration of inflammatory cell infiltration in airways after BUD-SSMs and Pulmicort Respules ${ }^{\circledR}$}

The experimental protocol (see Scheme 1) was designed to study the duration of budesonide inhibition with respect to total cell counts and differential cell counts in the bronchoalveolar lavage fluid of ovalbumin-sensitized and ovalbumin-challenged male Sprague-Dawley rats. The protocol for ovalbumin sensitization and challenge (Scheme 1) was modified from a previously published method. ${ }^{30}$ The experimental protocol was approved by the Animal Ethics Committee, Health Campus, Universiti Sains Malaysia. Pathogen-free male Sprague-Dawley rats (8-11 weeks of age) weighing $200 \pm 50 \mathrm{~g}$, were housed six per cage in the laboratory with free access to food and water, and maintained on a 12-hour dark/light cycle. Briefly, following acclimatization, the rats were randomly divided into four groups: Group A, untreated rats, required to illustrate and define the physiological norm of inflammatory cell infiltration (controls); Group B, rats sensitized by intraperitoneal injection of $100 \mu \mathrm{g}$ ovalbumin precipitated in $5 \mathrm{mg}$ aluminum hydroxide (ovalbumin precipitate) per rat on days 0,7 , and 14 (negative control) and used to assess the effect of sensitization on inflammatory cell infiltration; Group $\mathrm{C}$ rats, sensitized by intraperitoneal injection of $100 \mu \mathrm{g}$ ovalbumin precipitate on days 0,7 , and 14 , followed by anesthesia and intratracheal instillation of ovalbumin challenge (100 $\mu \mathrm{g} / \mathrm{rat}) 24$ hours after the last ovalbumin sensitization, ie, on day 14 (positive control), and used to assess the effect of ovalbumin challenge on inflammatory cell infiltration; and Group D, which comprised the treatment group, and was divided into nine subgroups as follows:

- Pulmicort Respules ${ }^{\circledR}$ group, in which treatment was administered via intratracheal instillation 23 hours (DP1), 12 hours (DP2), or one hour (DP3) before ovalbumin challenge.

- BUD:PEG ${ }_{5000}$-DSPE SSMs group (F43, A, intervention group, $\mathrm{n}=18$ ) in which treatment was administered via intratracheal instillation 23 hours (DIA1), 12 hours (DIA2), or one hour (DIA3) before ovalbumin challenge.

- Rehydrated PEG P000 $_{50}$-DSPE SSMs group (F39), in which treatment was administered via intratracheal instillation one hour (D1) before ovalbumin challenge to examine the pharmacodynamic effect of the placebo treatment on the ovalbumin model rats.

Rats were sensitized by intraperitoneal injection of $100 \mu \mathrm{g} /$ rat ovalbumin with $5 \mathrm{mg}$ aluminum hydroxide on days 0,7 , and 14 . They were anesthetized by intraperitoneal injection of ketamine + xylazine $(80 \mathrm{mg} / \mathrm{kg}+8 \mathrm{mg} /$ $\mathrm{kg}$ intraperitoneally $)^{31}$ and received intratracheal instillation of ovalbumin (100 $\mu \mathrm{g} / \mathrm{rat}) 24$ hours after the last ovalbumin sensitization using a Penn-Century Liquid MicroSprayer Aerosolizer $^{\circledR}$ (Model IA-1B, Penn-Century Inc, Wyndmoor, 


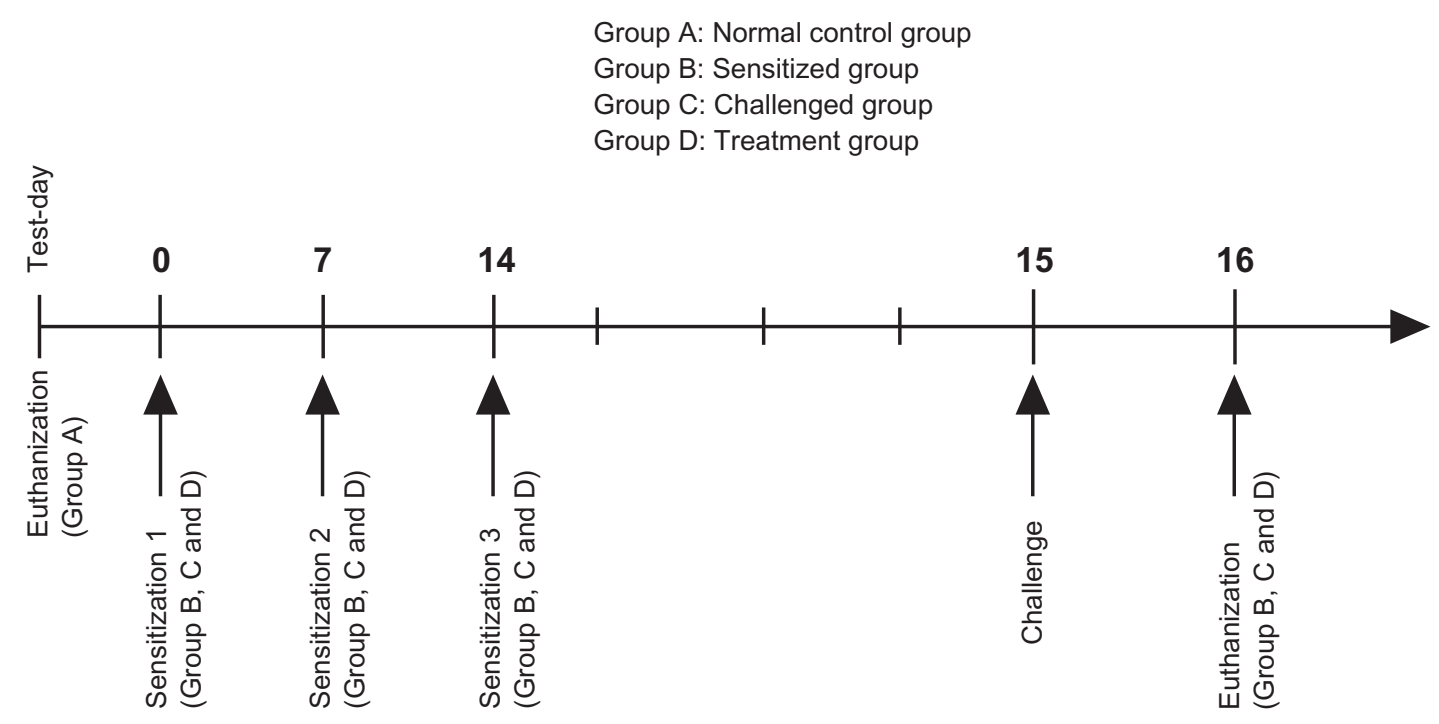

Scheme I Sensitization, challenge and treatment protocol.

PA) with the aid of a small animal laryngoscope (Model LS-2, Penn-Century Inc). At one hour, 12 hours, or 23 hours before ovalbumin exposure, $1 \mathrm{mg} / \mathrm{kg}$ of BUD-SSMs or Pulmicort Respules ${ }^{\circledR}$ was administered via intratracheal instillation. At 24 hours after ovalbumin challenge, the rats were euthanized in a carbon dioxide chamber, and the lungs with trachea were excised and lavaged.

Bronchoalveolar lavage was performed by flushing the airways with $5 \mathrm{~mL}$ of Dulbecco's phosphate-buffered saline (SAFC Biosciences, Kansas City, MO) through the tracheal cannula. The total leukocyte cell counts and differential cell counts of the bronchoalveolar lavage fluid were recorded by a single blinded expert in a private laboratory (Pro-Lab, Penang, Malaysia). The total leukocyte cell counts in the bronchoalveolar lavage fluid were determined using a hematocytometer. Cell smears $\left(8 \times 10^{4}\right.$ cells $\left./ \mathrm{mL}\right)$ were prepared by centrifugation in a bronchoalveolar lavage fluid centrifuge at $4000 \mathrm{rpm}$ for five minutes at $20^{\circ} \mathrm{C}$, after which the supernatants were removed and the cells were resuspended in Dulbecco's phosphate-buffered saline. Differential cell counts of 200 leukocytes (eosinophils, lymphocytes, neutrophils, and macrophages) were conducted for each animal under light microscopy ( $400 \times$ magnification). Briefly, a thin film of resuspended cells was obtained by spreading a drop of the cells evenly across a clean grease-free slide. A few drops of Leishman's stain (Laboratory Labchem Chemical, Selangor Darul Ehsan, Malaysia) were poured onto the slide, and after 3 minutes, 20 drops of buffered water were added. After a further 7 minutes, the stain was washed off with distilled water for 2-3 minutes, following which the slides were rinsed with tap water and stood in a rack to drain and dry in air. These methods are commonly employed and are fully described elsewhere. ${ }^{32,33}$ Percent inhibition of inflammatory cell infiltration into the airways was calculated according to the following equation:

$$
\begin{gathered}
\% \text { Inhibition }=\left(\frac{E_{P . \text { control }}-E_{\text {Group }}}{E_{P . \text { control }}-E_{N . \text { control }}}\right) \times 100 \\
\% \text { Inhibition }=\left(\left(E_{P . \text { cont }}-E_{\text {Group }}\right) /\left(E_{P \text {.cont }}-E_{\text {N.cont. }}\right)\right) * 100
\end{gathered}
$$

where $E_{\text {P.control, }}, E_{\text {N.control }}$, and $E_{\text {Group }}$ are inflammatory cell counts in bronchoalveolar lavage fluid in the positive control (Group C), negative control (Group B), and treatment group (Group D), respectively.

\section{Statistical analysis}

For statistical comparisons, analysis of variance with pairwise comparison and dependent and independent $t$-test procedures were used where applicable. A $P$ value of less than 0.05 was considered significant for all analyses.

\section{Results and discussion Drug loading and maximum solubility}

Budesonide was successfully incorporated into SSMs of $\mathrm{PEG}_{5000}$-DSPE using the coprecipitation and reconstitution method. The SSMs potential to solubilize budesonide was assessed with eight different budesonide concentrations ranging from 430.5 to $731.85 \mu \mathrm{g} / \mathrm{mL}$ in $5 \mathrm{mM} \mathrm{PEG}_{5000}$-DSPE. Surprisingly, all samples at or below $605.71 \pm 6.38 \mu \mathrm{g} / \mathrm{mL}$ of budesonide (drug-to-PEGylated polymer molar ratio of 0.28 ) had a single uniform size distribution determined by photon correlation spectroscopy; a second signal was 
observed above this concentration (Figure 1). For a given PEGylated polymer, the poorly soluble drug only solubilized up to a certain concentration of drug, and when the maximum threshold was achieved, populations of other species, namely sterically stabilized particles, were observed by photon correlation spectroscopy (Figure 2). ${ }^{34}$ The sterically stabilized particles were probably stabilized by the $\mathrm{PEG}_{5000}$-DSPE on their surfaces, which helped the steroids form aggregates and thus to maximize the hydrophobic interactions and hydrogen bonding network with water. ${ }^{20,21}$ Formulations containing sterically stabilized particles were not considered the optimum formulation due to difficulties reproducing the formulations, as previously reported..$^{20}$

\section{Hydrodynamic particle size and zeta potential of SSMs}

The particle size of the final rehydrated BUD-SSMs (drug to PEGylated polymer molar ratio of 0.28 ) was $21.51 \pm 1.5 \mathrm{~nm}$, with a narrow polydispersity index $(0.22 \pm 0.02)$ that did not differ significantly $(P>0.05)$ from that observed in the prelyophilization process $(20.45 \pm 1.65)$, indicating formation of SSMs with a typical particle size of polymeric micelles between 10 and $100 \mathrm{~nm} .{ }^{35}$ Due to their small size, the likelihood that BUD-SSMs would undergo phagocytosis in the alveoli is much lower than that for micron-sized particles, because it has been reported that particles of less than $260 \mathrm{~nm}$ can escape phagocytosis by macrophages. ${ }^{36}$

The zeta potential measurement gives an indication of the stability of the colloidal system. Dispersions with a large negative or positive zeta potential tend to have better stability against aggregation. ${ }^{37}$ The zeta potential of BUD-SSMs was $-28.43 \pm 1.98 \mathrm{mV}$, confirming the stability potential.
The negative charge of the BUD-SSM formulation also gives it a potential advantage as a drug carrier because it has been reported that negatively charged particles are retained in the lungs more efficiently than positively charged molecules. ${ }^{38}$

\section{Drug loading, yield, and entrapment efficiency of BUD-SSMs}

According to the spectrophotometric and particle size analysis, all budesonide molecules were incorporated into the SSMs after lyophilization. This was supported by the lack of a significant difference $(P>0.05)$ in percentage entrapment efficiency before (100.49 \pm 1.06$)$ and after lyophilization (100.13 \pm 1.09$)$. In addition, the BUD-SSM formulations had a high percentage yield $(97.98 \pm 1.95)$ and considerable percentage drug loading $(2.01 \% \pm 0.02 \%)$. The percentage drug loading value was consistent with findings for other steroid formulations. ${ }^{39,40}$ In addition, the BUD-SSMs formed from PEG $_{5000}$-DSPE were robust to the lyophilization conditions, with the lyophilized cakes having a fluffy and elegant appearance and dissolving easily upon reconstitution with distilled water to form clear and colorless solutions. This was due to the hydrophilic PEG polymer on the outer surface (corona), which can act as both a cryoprotectant and a lyoprotectant. ${ }^{20} \mathrm{~A} 5 \mathrm{mM}$ concentration of $\mathrm{PEG}_{5000}$-DSPE was appropriate for lyophilization because high-density PEG blocks can serve as a steric barrier between hydrophobic cores and prevent contact between and agglomeration of the core materials of the micelles, as previously reported when using $10 \mathrm{mM} \mathrm{PEG}_{2000}$-DSPE. ${ }^{17,21}$

\section{Differential scanning calorimetry study}

Differential scanning calorimetry analysis was performed to determine the nature of the drug inside the polymer

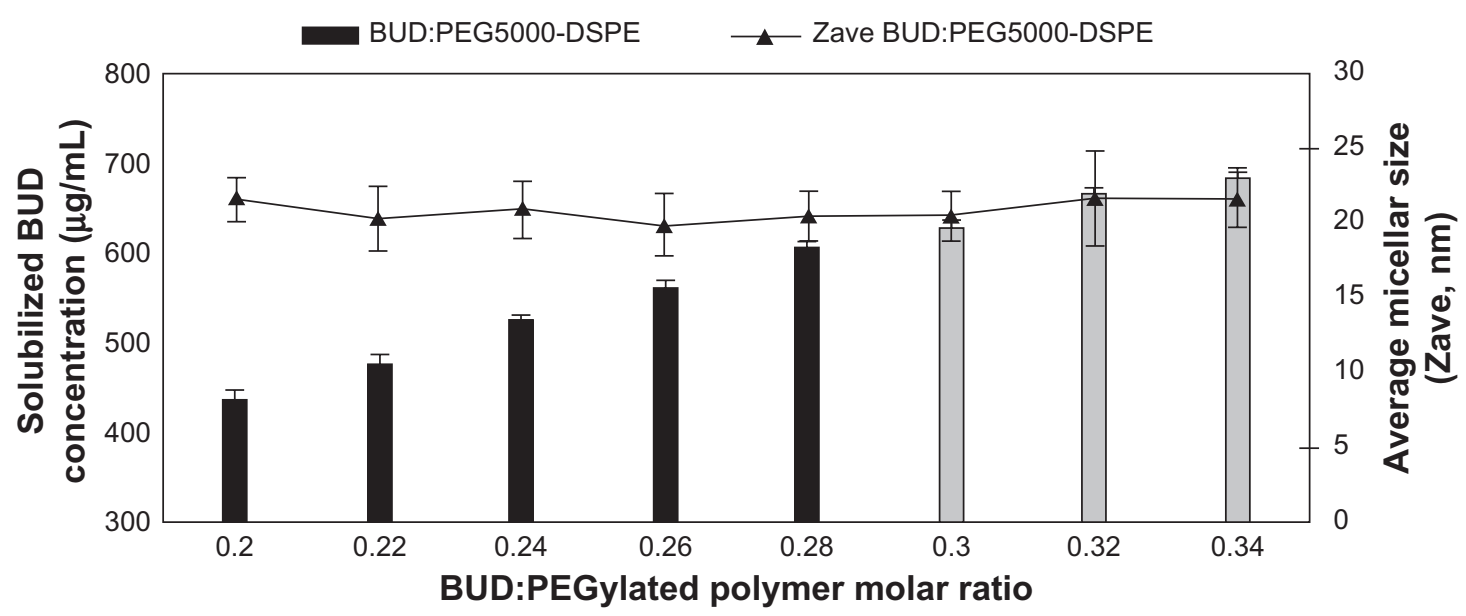

Figure I Effect of the budesonide: PEGylated polymer molar ratio on solubilization of budesonide; PEGylated polymer molar concentration kept at 5 mM. Note: Gray bars indicate second population signal in photon correlation spectroscopy. 

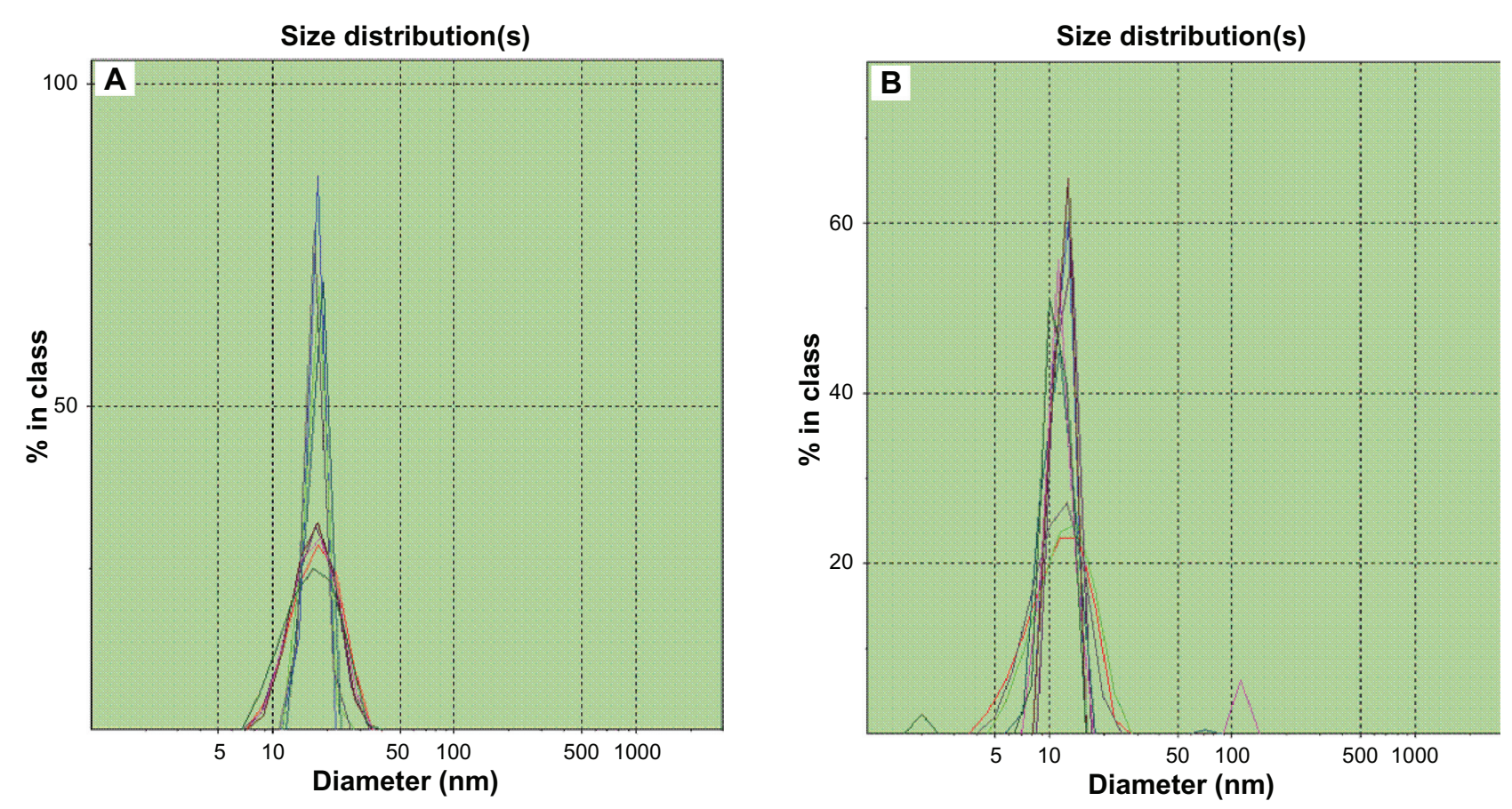

Figure 2 Photon correlation spectroscopic size distribution of BUD-SSMs. (A) BUD-SSMs at optimum drug concentration (0.28 drug to polymer molar ratio); (B) BUD-SSMs at excessive drug concentration ( 0.30 drug to polymer molar ratio).

Abbreviation: BUD-SSMs, PEG $_{5000}$-DSPE polymeric micelles containing budesonide.

matrix (molecular dispersion or in crystallized form). ${ }^{41}$ The differential scanning calorimetry thermograms for the various budesonide samples are shown in Figure 3. Budesonide melted at approximately $261.58^{\circ} \mathrm{C} \pm 0.32^{\circ} \mathrm{C}$. The melting peak for $\mathrm{PEG}_{5000}-\mathrm{DSPE}$ was at $59.91^{\circ} \mathrm{C} \pm 0.04^{\circ} \mathrm{C}$. The peaks of the physical mixtures of budesonide and $\mathrm{PEG}_{5000^{-}}-\mathrm{DSPE}$ were approximately $256^{\circ} \mathrm{C} \pm 2.27^{\circ} \mathrm{C}$ and $59.82^{\circ} \mathrm{C} \pm 0.09^{\circ} \mathrm{C}$, respectively, with a sharp decrease in the peak intensity for budesonide. Samples of the lyophilized BUD-SSMs gave only one peak at approximately $58.08^{\circ} \mathrm{C} \pm 0.17^{\circ} \mathrm{C}$ for $\mathrm{PEG}_{5000}$-DSPE, with no endothermic budesonide peak. These results indicated that the physical mixing of budesonide and PEGylated polymer did not affect the structure of the block copolymer. Conversely, BUD-SSMs caused a slight but significant $(P<0.05)$ downward shift in the endothermic peak of the PEGylated polymer, which indicated that there were physical interactions between budesonide and the PEGylated polymer. The interaction suggested that budesonide was molecularly dispersed in the PEGylated polymer matrix. The disappearance of the endothermic peak of budesonide at low drug concentrations in the BUD-SSMs was due to its complete miscibility in the molten PEGylated polymer. However, at higher drug ratios (physical mixture), only partial miscibility was achieved, and the drug only began to melt at $249^{\circ} \mathrm{C} \pm 2.00^{\circ} \mathrm{C}$. Similar results were reported in a study of the interaction between $\mathrm{PEG}_{6000}$ and oxazepam. ${ }^{42}$
Zhang et al showed that the glass transition temperature of paclitaxel-loaded polymeric nanoparticles from differential scanning calorimetry analysis was lower than that of the polymeric blanks, which suggested that the descent peak shift might be an indication that the drug is either molecularly dispersed in the block copolymer or distributed in the block copolymer in an amorphous state. ${ }^{43}$

\section{Fourier transform infrared spectroscopy}

The Fourier transform infrared spectrum of budesonide showed carbonyl stretching bands at 1725 and $1662 \mathrm{~cm}^{-1}$ (Figure 4). Vibrations in the $1600-1900 \mathrm{~cm}^{-1}$ regions indicated a $\mathrm{C}=\mathrm{O}$ stretch. The budesonide molecule has two $\mathrm{C}=\mathrm{O}$ groups, ie, a dihydrobenzoquinone $\mathrm{C}=\mathrm{O}$ group and an acetyl $\mathrm{C}=\mathrm{O}$ group. Typically, acetyl $\mathrm{C}=\mathrm{O}$ and dihydrobenzoquinone $\mathrm{C}=\mathrm{O}$ groups exhibit stretching bands in the regions of $1700-1900 \mathrm{~cm}^{-1}$ and $1600-1750 \mathrm{~cm}^{-1}$, respectively. Thus, the bands at $1725 \mathrm{~cm}^{-1}$ and $1662 \mathrm{~cm}^{-1}$ in the budesonide spectrum corresponded to the nonconjugated acetyl $\mathrm{C}=\mathrm{O}$ stretch and conjugated dihydrobenzoquinone $\mathrm{C}=\mathrm{O}$ groups, respectively. ${ }^{44}$ In addition, there was a $(\mathrm{OH})$ vibrational band at $3486 \mathrm{~cm}^{-1}$. The physical mixture of budesonide and the PEGylated polymers $\left(\mathrm{PEG}_{5000}\right.$-DSPE) showed similar spectra. However, the lyophilized BUD-SSMs exhibited a small shift in the conjugated $\mathrm{C}=\mathrm{O}$ stretching band from 1662 to $1667 \mathrm{~cm}^{-1}$. This shift was caused by an altered 


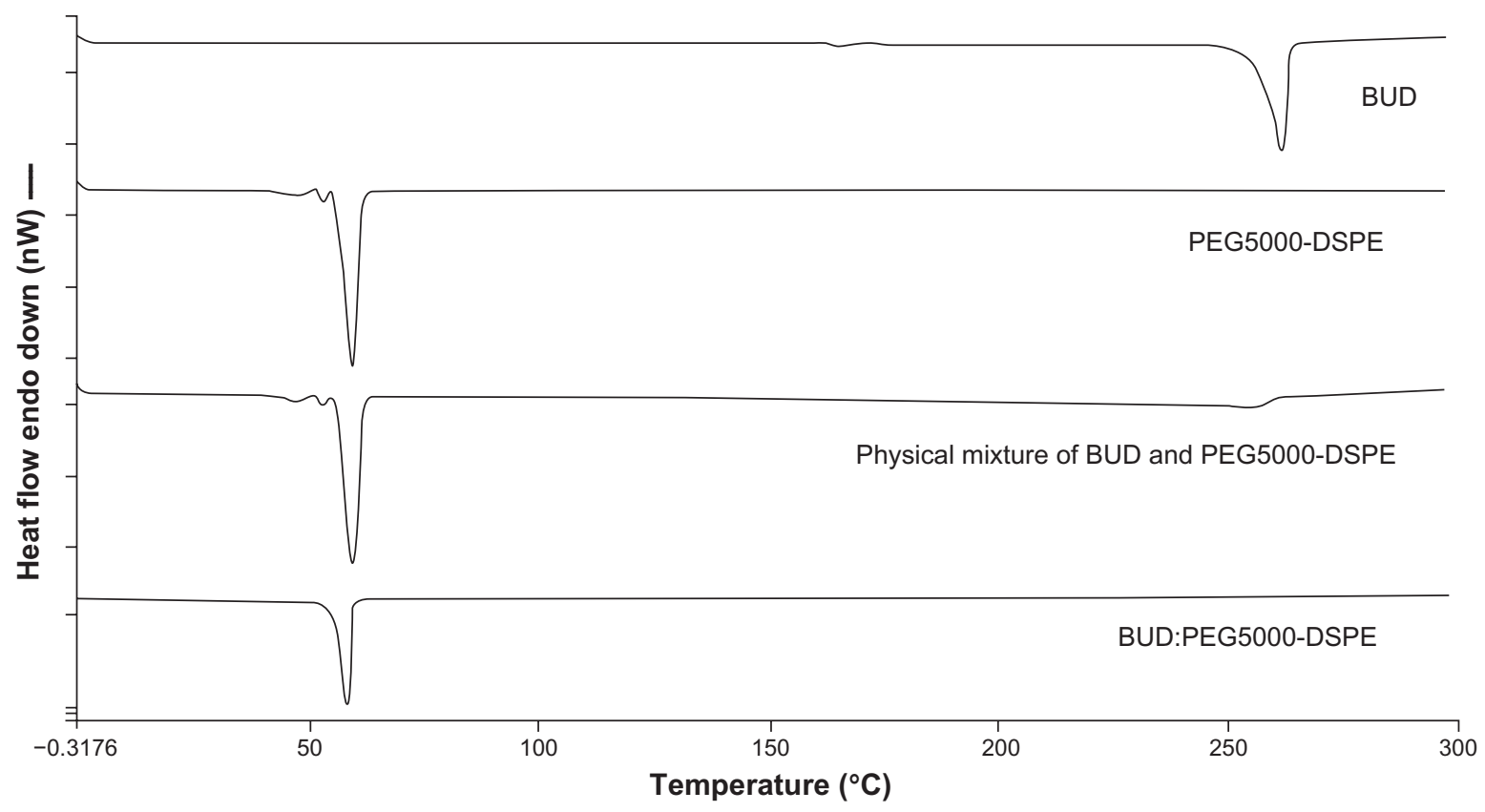

Figure 3 Differential scanning calorimetric thermograms of budesonide, PEG $_{5000}$-DSPE, physical mixture and BUD-SSMs.

Abbreviations: BUD-SSMs, PEG ${ }_{5000}$-DSPE polymeric micelles containing budesonide; PEG $_{5000}$-DSPE, I,2-distearoyl-sn-glycero-3-phosphoethanolamine-N-methoxypoly(ethylene glycol 5000).

environment around the interatomic $\mathrm{C}=\mathrm{O}$ bonds due to the solvation process in the hydrophobic portion of the PEGylated polymer. Formation of intermolecular hydrogen bonds between the $\mathrm{OH}$ group of budesonide and the $\mathrm{C}=\mathrm{O}$ groups of the PEGylated polymer may explain this shift. Conversely, there was no shift in the nonconjugated $\mathrm{C}=\mathrm{O}$ of budesonide. In addition, the vibration band of $(\mathrm{OH})$ for both budesonide and the PEGylated polymer changed to a broad peak. Changes in the Fourier transform infrared spectrum of budesonide have also been reported by other investigators. Tajber et al showed that spray-dried budesonide exhibited a shift in the conjugated $\mathrm{C}=\mathrm{O}$ stretching band when converted from the crystalline to the amorphous form..$^{45}$ In addition, they found that the $\mathrm{OH}$ bands appeared as a broad peak located in the $3300-3700 \mathrm{~cm}^{-1}$ regions. They suggested a possible change in the environment of the conjugated $\mathrm{C}=\mathrm{O}$ group of budesonide. As a result, no pronounced interactions were identified between budesonide and the PEGylated polymer because the entire relevant spectral band (conjugated and nonconjugated $\mathrm{C}=\mathrm{O}$ band) had not disappeared, which would indicate that the budesonide molecules were in an amorphous state. This result was confirmed by differential scanning calorimetry analysis.

\section{Morphology of BUD-SSMs}

Transmission electron microscopy is commonly used to examine nanoscopic colloids such as SSMs. The mean diameter of these SSMs was measured directly from randomly selected formulations in transmission electron microscopic images. The mean particle size of BUD-SSMs was $104.08 \pm 27.30 \mathrm{~nm}$ (Figure 5). These measurements differed significantly from those obtained by photon correlation spectroscopy. This was due to the tendency for particles to aggregate as a result of the drying process during sample preparation for transmission electron microscopy, as also reported by other researchers. ${ }^{46}$ Closer observation of the BUD-SSMs revealed spherical nanoparticles with bright and dark areas and a core-shell with a multivesicular appearance.

\section{Solubility and budesonide release from SSMs}

The equilibrium dialysis method was used to determine the solubility of poorly water-soluble corticosteroids because it enabled drug equilibration to be achieved. Furthermore, it overcame the inherent wetting problem of these highly hydrophobic powders and minimized errors associated with sample processing. ${ }^{24}$ The aim of the solubility study was to calculate the concentration that was required for the drugrelease studies under the sink condition.

Budesonide has low solubility in phosphate-buffered saline $(21.95 \pm 1.15 \mu \mathrm{g} / \mathrm{mL})$ and this result was consistent with previously reported results $(23 \mu \mathrm{g} / \mathrm{mL}) .{ }^{24}$ The sink condition is achieved if the final concentration of the drug in the dissolution medium is less than $20 \%$ of the saturation solubility of the 


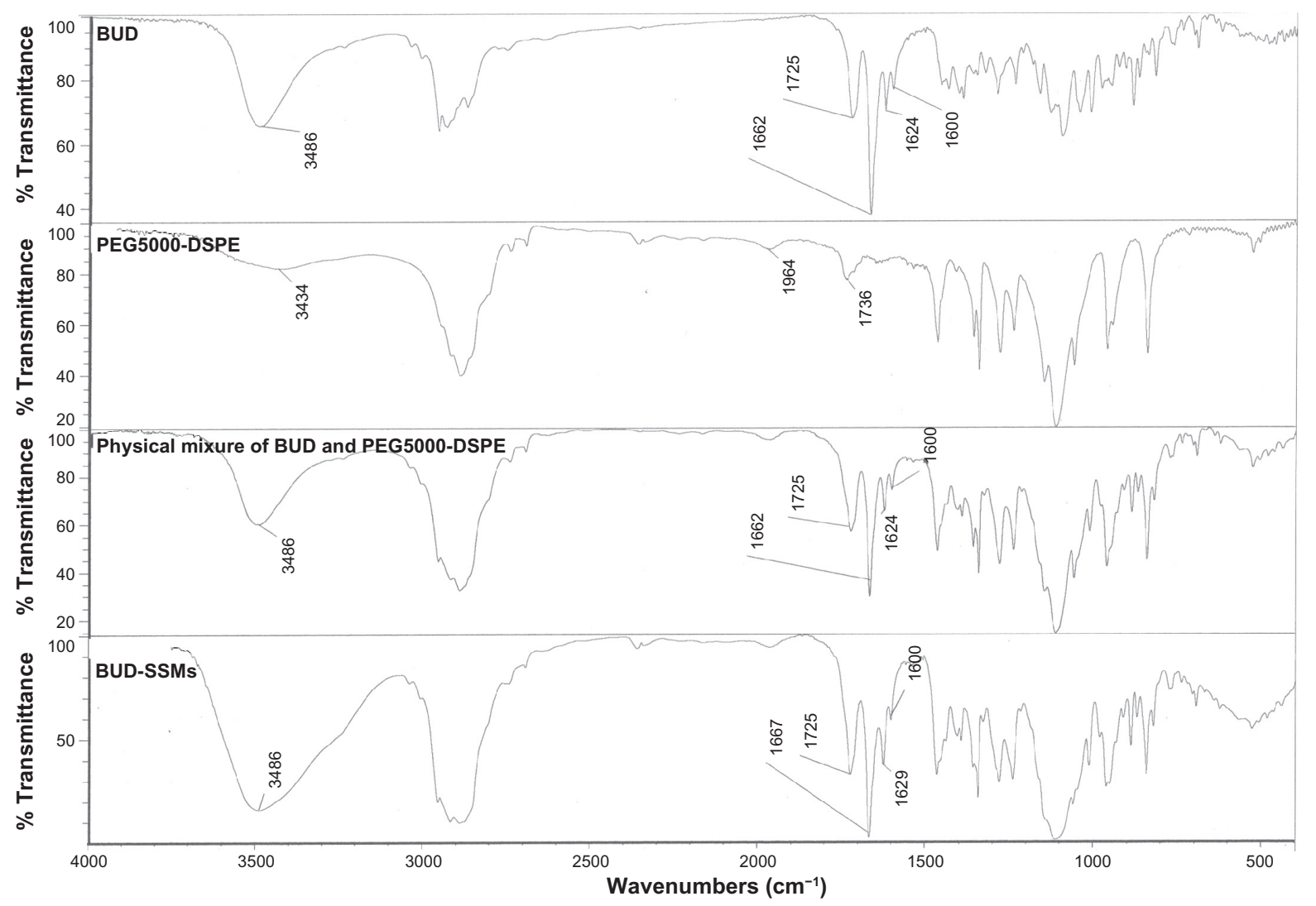

Figure 4 Fourier transform infrared spectra of budesonide, PEG $_{5000}$-DSPE, physical mixture, and BUD-SSMs.

Abbreviations: BUD-SSMs, PEG ${ }_{5000}$-DSPE polymeric micelles containing budesonide; PEG $_{5000}$-DSPE, I,2-distearoyl-sn-glycero-3-phosphoethanolamine-N-methoxypoly(ethylene glycol 5000).

drug. ${ }^{47}$ The final concentration of budesonide after complete release in phosphate-buffered saline was less than $4.39 \mu \mathrm{g} / \mathrm{mL}$ and was consistent with the sink condition.

Comparison of the dissolution release profiles for BUD-SSMs and Pulmicort Respules ${ }^{\circledR}$ at the end of the first

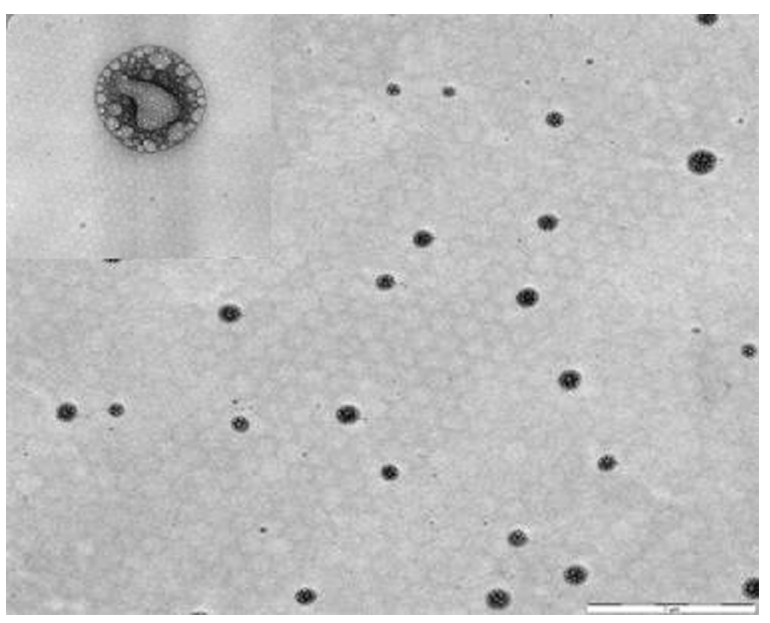

Figure 5 Morphological examinations of BUD-SSMs by transmission electron microscopy.

Note: Scale bar $=I \mu \mathrm{m}$ and $50 \mathrm{~nm}$.

Abbreviation: BUD-SSMs, PEG $_{5000}$-DSPE polymeric micelles containing budesonide.
6 hours revealed that more than $90 \%$ of budesonide was released from Pulmicort Respules ${ }^{\circledR}$, while less than $35 \%$ of budesonide was released from BUD-SSMs, with completion of release within 6 days (Figure 6). The drug release kinetics (Table 1) of the various preparations were evaluated by fitting the release data to the zero-order, first-order, and Higuchi equations using the DDSolver software. The most appropriate drug-release model was selected based on its highest adjusted coefficient of determination ( $\mathrm{R}^{2}$ adjusted) value and lowest Akaike information criterion. BUD-SSMs best fitted the Higuchi release kinetics $(P<0.05)$. In contrast, Pulmicort Respules ${ }^{\circledR}$ followed first-order release kinetics $(P<0.05)$.

According to the Higuchi model, two possible mechanisms may be involved in drug release from BUD-SSMs, ie, diffusion of the drug from the micelles and micelle erosion resulting from the degradation of the PEGylated polymer. In order to determine the best possible mechanism, release data for the BUD-SSMs were fitted to the Baker-Lonsdale and Hixson-Crowell models. The Baker-Lonsdale model best describes the release of drug incorporated in a spherical matrix following the diffusion mechanism, while the 


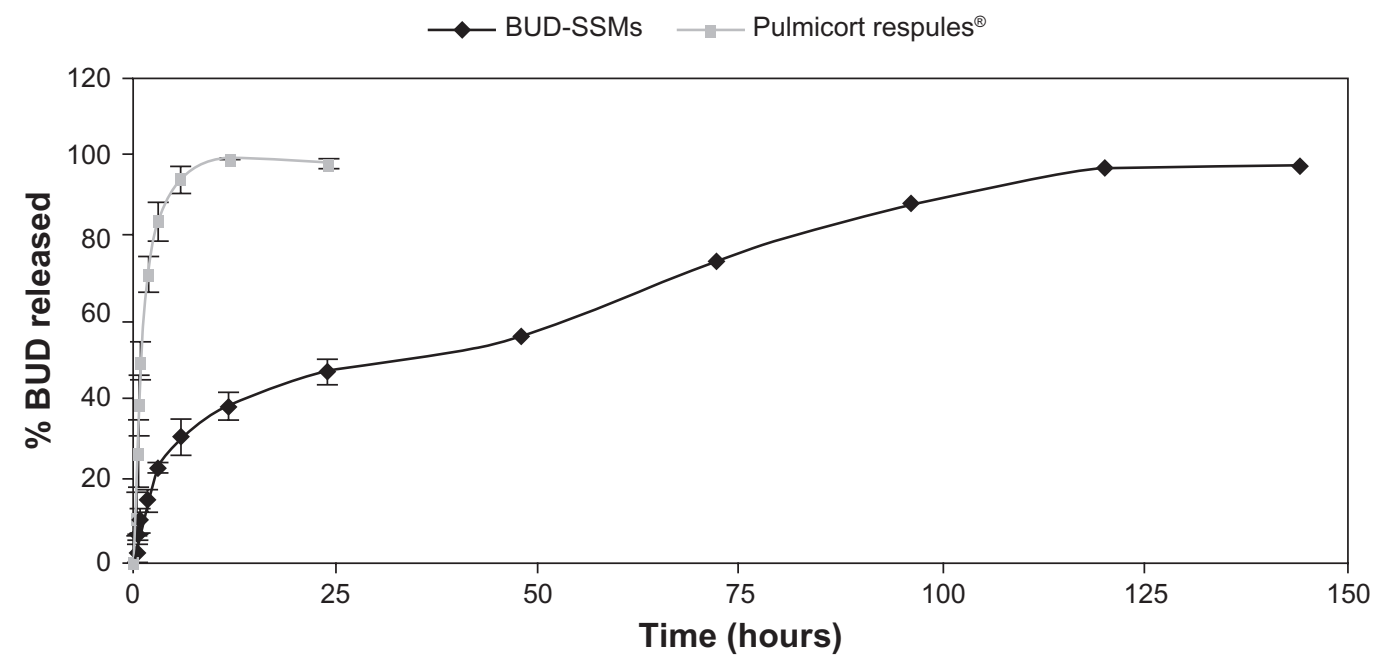

Figure 6 Drug-release profiles of BUD-SSMs and Pulmicort Respules ${ }^{\circledR}$.

Abbreviation: BUD-SSMs, PEG $_{5000}$-DSPE polymeric micelles containing budesonide.

Hixson-Crowell model best describes the release of drug from the delivery system according to the change in surface area and diameter of the particles over time. ${ }^{48-50}$ The results showed that the BUD-SSMs most closely followed the Baker-Lonsdale model $(P<0.05)$ and further supported the postulation that the release of budesonide from SSMs is more consistent with a diffusion mechanism than a matrix erosion mechanism. Derakhshandeh et al reported a similar result with 9-nitrocamptothecin-PLGA-PEG nanoparticles, where drug release followed the diffusion mechanism using the Baker-Lonsdale model. ${ }^{50}$ Abdulla et al found that the release profile of rifampicin-SSMs followed both the firstorder and Higuchi kinetics models. ${ }^{51}$ However, they only used the correlation coefficient to evaluate the goodness of fit. In our study, there were insignificant differences among the $\mathrm{R}^{2}$ adjusted values following the first-order and Higuchi equation $(P>0.05)$, while significant $(P<0.05)$ differences were observed among the Akaike information criterion values for the SSM formulations following the first-order $(94.47 \pm 1.67)$ and Higuchi equations $(77.82 \pm 3.90)$. Our results indicated that using only a single criterion to evaluate the goodness of fit is not sufficient. When comparing several models, the model with the smallest Akaike information criterion value is a further indication for the best goodness of fit. In addition, from a statistical point of view, the $\mathrm{R}^{2}$ adjusted value is regarded as a more powerful measure than the unadjusted coefficient of $\mathrm{R}^{2}$ determination. ${ }^{52}$

Many methods can be used to compare in vitro drugrelease profiles. For the analysis of variance (ANOVA)-based method, the most suitable approach is to use repeated measures ANOVA because the release data comprise repeated measurements collected over time during the same experiment (ie, time is the repeated factor and percent drug released is the dependent variable). Repeated measures ANOVA is regarded as a more precise method than independent or paired $t$-tests..$^{53}$ The one-way ANOVA method compares pairs of values at each time point but ignores the correlation between the dissolution time points (this method treats each time point as independent of the other, which is definitely not the case).${ }^{54}$ Repeated measures ANOVA has been used in many studies. ${ }^{53,55-57}$

The model-dependent method evaluates the dissolution profiles using different model parameters $\left(\mathrm{eg}, \mathrm{t}_{50 \%}\right.$, release rate constant).$^{53}$ This method cannot be used to compare

Table I Kinetic drug release values of different budesonide formulations

\begin{tabular}{|c|c|c|c|c|c|c|c|c|c|}
\hline \multirow[t]{2}{*}{ Preparations } & \multicolumn{5}{|c|}{ Adjusted coefficient of determination ( $R^{2}$ adjusted) } & \multicolumn{4}{|c|}{ Release rate constant } \\
\hline & $\begin{array}{l}\text { Zero- } \\
\text { order }\end{array}$ & $\begin{array}{l}\text { First- } \\
\text { order }\end{array}$ & Higuchi & $\begin{array}{l}\text { Baker- } \\
\text { Lonsdale } \\
\text { model }\end{array}$ & $\begin{array}{l}\text { Hixson- } \\
\text { Crowell } \\
\text { model }\end{array}$ & $\begin{array}{l}\text { Zero-order } \\
\left(\mathbf{K}_{0}\right) \\
\text { ( } \mu \text { g/hour) }\end{array}$ & $\begin{array}{l}\text { First-order } \\
\text { (kl) } \\
\text { (per hour) }\end{array}$ & $\begin{array}{l}\text { Higuchi } \\
(\mathrm{kH}) \\
\left(\mu \mathrm{g} / \mathrm{h}^{0.5}\right)\end{array}$ & $\begin{array}{l}\text { Baker- } \\
\text { Lonsdale }\end{array}$ \\
\hline BUD-SSMs & $0.76 \pm 0.05$ & $0.91 \pm 0.01$ & $0.97 \pm 0.01$ & $0.97 \pm 0.01$ & $0.88 \pm 0.01$ & 1 & I & $9.04 \pm 0.48$ & $0.002 \pm 0.00$ \\
\hline Pulmicort & $0.23 \pm 0.30$ & $0.98 \pm 0.01$ & $0.90 \pm 0.03$ & I & l & l & $0.65 \pm 0.09$ & I & I \\
\hline Respules ${ }^{\circledR}$ & & & & & & & & & \\
\hline
\end{tabular}

Abbreviation: BUD-SSMs, PEG $_{5000}$-DSPE polymeric micelles containing budesonide. 
the release profiles of formulations having different release mechanisms. ${ }^{58}$ The estimated model parameters can be compared statistically using the $t$-test. ${ }^{26,58}$ The third method for comparison of in vitro release is the model-independent method (using similarity and difference factors), but this was not used in this study because the coefficients of variation (release profile within batch) during the first $15 \mathrm{~min}$ utes were higher than $15 \% .^{48,54,58}$ When the results of our study were analyzed, the repeated measures ANOVA and one-way ANOVA showed that there were significant differences between the percent of drug released from Pulmicort Respules $^{\circledR}$ and BUD-SSMs. These results indicated that the corticosteroid-loaded SSMs successfully prolonged the in vitro drug release in comparison with the reference product.

\section{Aerodynamic characterization}

To demonstrate the ability to nebulize BUD-SSM formulations, aerodynamic parameters were studied using a next generation impactor connected to a Pari LC nebulizer and comparisons were made with a commercially available product (Pulmicort Respules ${ }^{\circledR}$ ). The aerodynamic distribution and characteristics of Pulmicort Respules ${ }^{\circledR}$ using the Pari LC nebulizer have previously been reported. ${ }^{23}$ The aerodynamic characteristics are shown in Table 2. The mass median aerodynamic diameter of BUD-SSMs was significantly smaller than that of the Pulmicort Respules ${ }^{\circledR}$. These results were due to the formulation effect. Solutions (our formulations) and microsuspensions (Pulmicort Respules ${ }^{\circledR}$ ) behave differently during nebulization. The particles in Pulmicort Respules ${ }^{\mathbb{R}}$ are $2-3 \mu \mathrm{m}$ in size, as reported by other researchers, while the particle size of the BUD-SSMs is $20.45 \pm 1.64 \mathrm{~nm} .{ }^{59}$ The nebulized suspension will therefore generate larger aerosol droplets (ie, larger mass median aerodynamic diameter

Table 2 Aerodynamic characteristics of different budesonide formulations

\begin{tabular}{lcr}
\hline Preparations & Pulmicort Respules $^{\circledR}$ & BUD-SSMs \\
\hline MMAD $(\mu \mathrm{m})$ & $4.48 \pm 0.12$ & $2.83 \pm 0.08$ \\
GSD $(\mu \mathrm{m})$ & $2.01 \pm 0.03$ & $2.33 \pm 0.04$ \\
ED $(\%)$ & $39.73 \pm 0.53$ & $59.13 \pm 0.19$ \\
FPF $_{(<2.8 \mu \mathrm{m})}(\%)$ & $15.48 \pm 0.61$ & $36.51 \pm 0.19$ \\
FPF $_{(<4.4 \mu \mathrm{m})}(\%)$ & $29.76 \pm 0.36$ & $52.31 \pm 0.25$ \\
Percent of drug remaining & $56.38 \pm 1.40$ & $40.70 \pm 0.63$ \\
in nebulizer & & \\
Percent of drug deposited & $4.39 \pm 0.66$ & $2.24 \pm 0.27$ \\
in induction port & & \\
\hline
\end{tabular}


MMAD, mass median aerodynamic; GSD, geometric standard deviation; ED, emitted dose; FPF, fine particle fraction. values) containing a smaller number of suspended particles (2-3 $\mu \mathrm{m})$, whereas the aerosolized SSM droplets are smaller (with lower mass median aerodynamic diameter values) and contain many thousands of nanoparticles. ${ }^{60}$

This postulation can be proved by using simple theoretical calculations, as suggested elsewhere. ${ }^{60}$ The average droplet size produced by Pari LC nebulizers is approximately 4 to $5 \mu \mathrm{m}$ according to the manufacturer. As such, the maximum particle load for an average $4.5 \mu \mathrm{m}$ diameter droplet generated by the nebulizers can be estimated using the following calculations:

$$
\text { Volume of sphere }=\frac{4}{3} \pi\left(\frac{d}{2}\right)^{3}
$$

where $d$ is the diameter of the droplet in $\mu \mathrm{m}$ and $\pi=3.14$.

The volume of an average $4.5-\mu \mathrm{m}$ droplet produced by the nebulizer will be:

$$
=\frac{4}{3} \pi\left(\frac{4.5}{2}\right)^{3}=47.69 \mu m^{3}
$$

The volume of a $2 \mu \mathrm{m}$ Pulmicort Respules ${ }^{\circledR}$ particle (the lowest value) will be:

$$
=\frac{4}{3} \pi\left(\frac{2}{2}\right)^{3}=4.19 \mu m^{3}
$$

The approximate volume of a $20 \mathrm{~nm}(0.02 \mu \mathrm{m}) \mathrm{SSM}$ particle will be:

$$
=\frac{4}{3} \pi\left(\frac{0.02}{2}\right)^{3}=4.19 \times 10^{-6} \mu^{3}
$$

Number of particles per 4.5- $\mu \mathrm{m}$ droplet

$$
=\left(\frac{\text { volume of } 4.5 \mu \mathrm{m} \text { droplet }}{\text { volume of drug particle }}\right)
$$

The number of $2 \mu \mathrm{m}$ Pulmicort Respules ${ }^{\circledR}$ particles per 4.5- $\mu \mathrm{m}$ droplet will be:

$$
=\left(\frac{47.69}{4.19}\right)=7.99 \text { particles per droplet }
$$

The number of $20 \mathrm{~nm}$ SSM particles per $4.5-\mu \mathrm{m}$ droplet will be:

$$
=\left(\frac{47.69}{4.19 \times 10^{-6}}\right)=7.99 \times 10^{6} \text { particles per droplet }
$$

Thus, based on the above calculations, it is possible in theory to pack as many as $7.99 \times 10^{6} \mathrm{SSM}$ nanoparticles of size $20 \mathrm{~nm}$ into a $4.5 \mu \mathrm{m}$ diameter droplet as opposed to only 7.99 Pulmicort Respules ${ }^{\circledR}$ particles of 4 to $5 \mu \mathrm{m}$ diameter into 
a similar droplet. This concept is based on the fact that there is a 100 -fold difference in the particle diameter and that the volumetric manipulation is a cubic relationship. Of course, this situation also assumes that the particles are perfectly spherical in shape and does not demonstrate the effect of drug concentration in the formulation. All values for mass median aerodynamic diameter, emitted dose, fine particle fraction, percent of drug remaining in the nebulizer, and percent of drug deposited in the induction port of the BUD-SSMs were significantly superior compared with Pulmicort Respules ${ }^{\circledR}$ due to the particle size and presence of the hydrophilic polymer (PEG) in the outer shell of the SSMs, which induced a repulsive steric interaction between the particles that could effectively decrease the overall adhesive forces, thereby allowing more efficient aerosolization and stabilizing the colloidal suspension in air. ${ }^{29,61,62}$ The geometric standard deviation values of
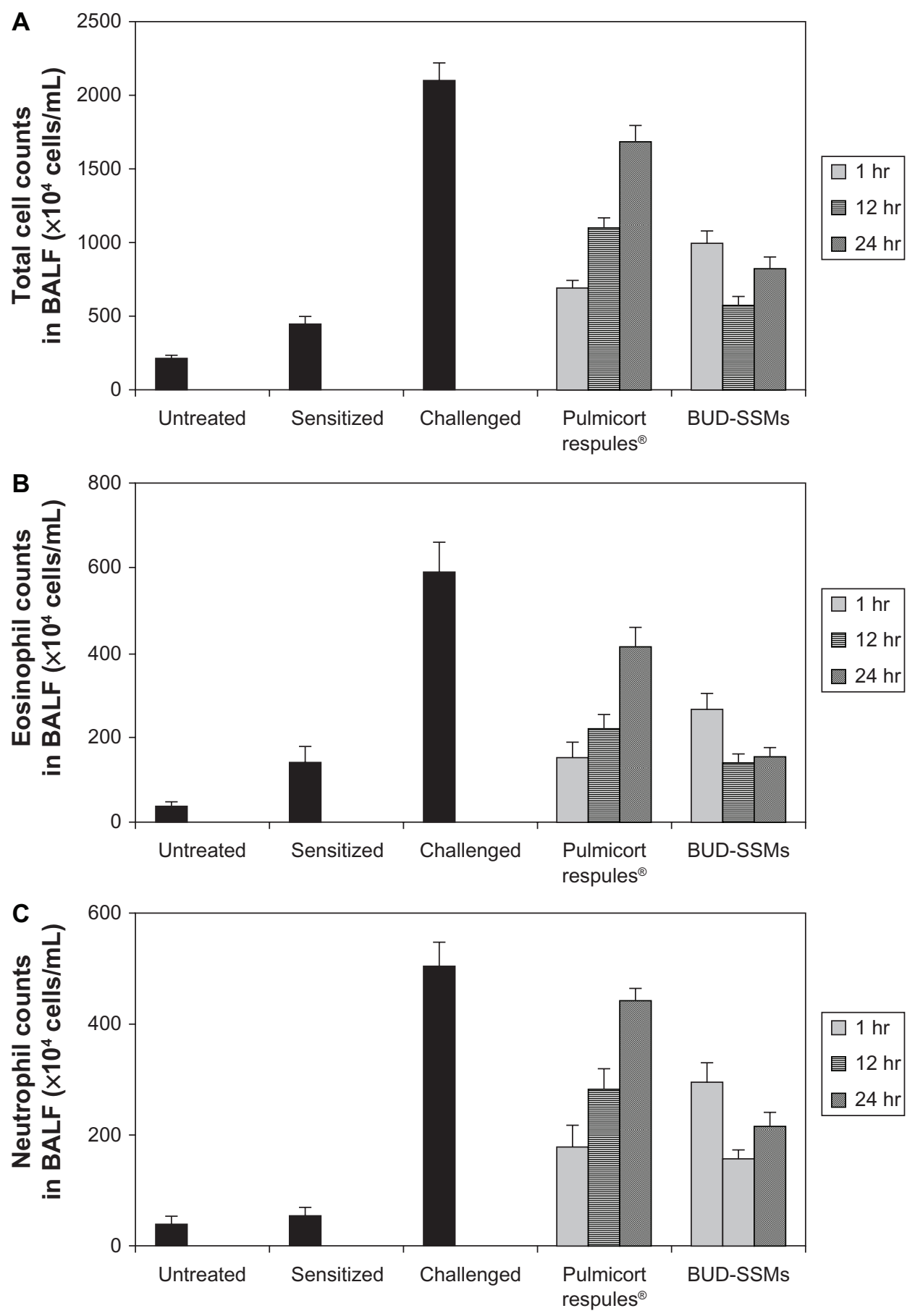

Figure 7 (Continued) 


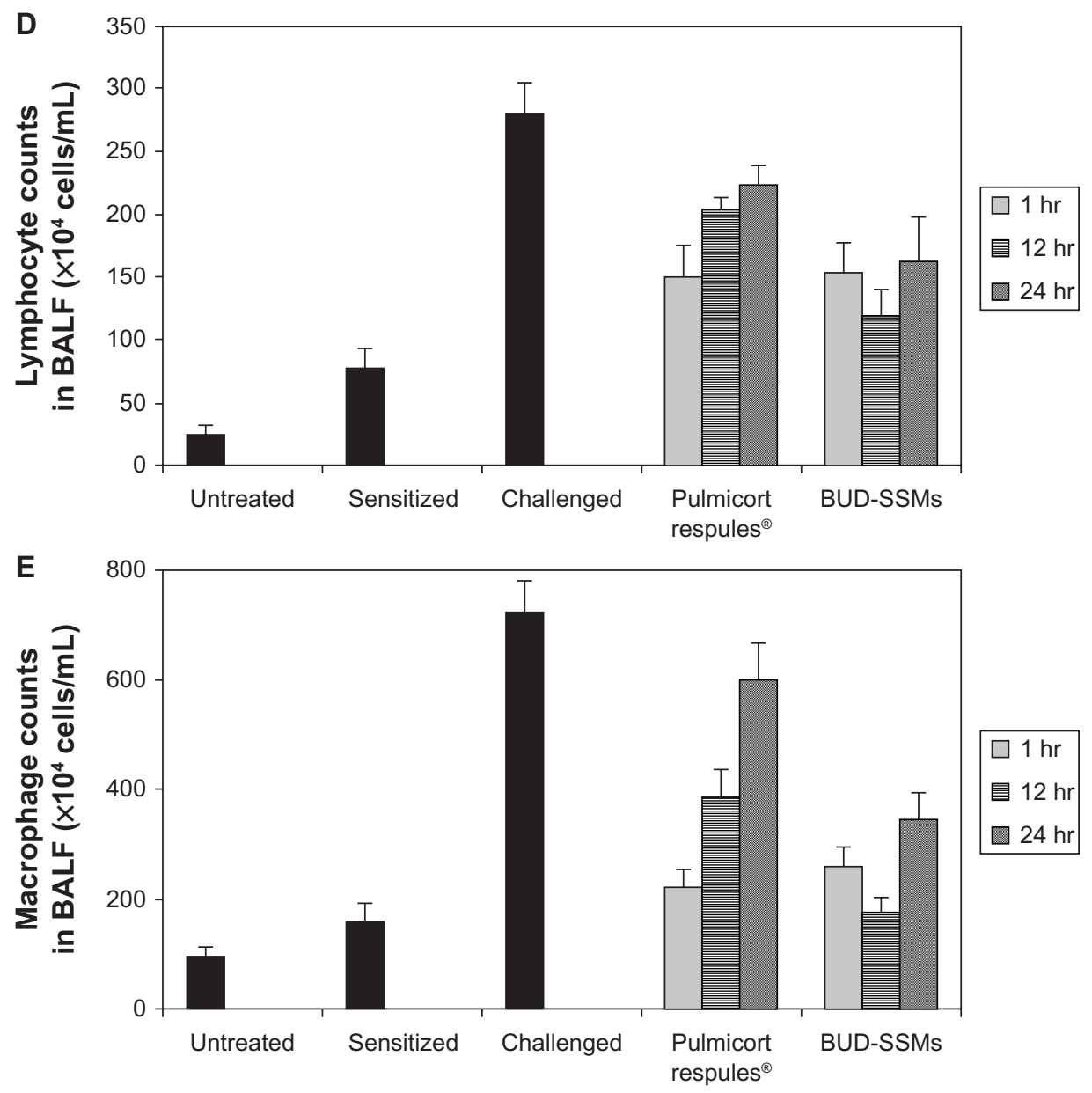

Figure 7 Total cell counts (A), eosinophil counts (B), neutrophil counts (C), lymphocyte counts (D), and macrophage counts (E) in bronchoalveolar lavage fluid in each experimental group of animals.

Notes: Error bar represents the standard error of the mean. for $n=6$. Untreated, no sensitization or challenge; sensitized (negative control), multiple antigen sensitization, no challenge; challenged (positive control), multiple antigen sensitization with challenge.

BUD-SSMs were significantly $(P<0.05)$ higher than those of the Pulmicort Respules ${ }^{\circledR}$ due to the effect of operating the cascade impactor at ambient temperature, which affected smaller droplets more than the larger droplets generated by the nebulizer, and produced a wider spread of geometric standard deviation values, as previously reported. ${ }^{63}$ The improved aerodynamic performance of the BUD-SSMs leads to a decrease in the therapeutic dose and a reduction in systemic side effects.

\section{Inhibitory duration of inflammatory cell infiltration in airways following BUD-SSMs and Pulmicort Respules ${ }^{\circledR}$}

Ovalbumin-sensitized animals are commonly used as an asthma/chronic obstructive pulmonary disease model, because recurrent exposure of ovalbumin in actively immunized rats induces production of ovalbumin-specific $\mathrm{IgE}$, airway hyperresponsiveness, peribronchial inflammation, and an increase in eosinophilia, neutrophilia, lymphocytes, and macrophages in bronchioalveolar lavage fluid. ${ }^{64}$ Challenge with ovalbumin led to a significant inflammatory response $(P<0.05)$ in the airways of sensitized SpragueDawley rats according to changes in total and differential cell counts of inflammatory cells in the bronchioalveolar lavage fluid in comparison with the untreated and sensitized groups (Figure 7). Treatment with Pulmicort Respules ${ }^{\circledR}$ or with BUD-SSMs one hour before challenge $(1 \mathrm{mg} / \mathrm{kg})$ reduced inflammatory cell infiltration $(P<0.05)$ in comparison with the challenged group (Figure 7). However, this inhibitory effect was significantly attenuated $(P<0.05)$ when the same dose of Pulmicort Respules ${ }^{\circledR}$ was administered 12 or 24 hours before the final challenge in comparison with the BUD-SSM formulations. Although the inhibitory effect was reduced, the results differed significantly from those of the positive group $(P<0.05)$. This is because the inhaled budesonide formed its fatty acid ester in the lung (budesonide-21 oleate), hence prolonging its half-life in the lung to $18-20$ hours 
Table 3 Inhibitory duration of inflammatory cell infiltration after intratracheal instillation of different budesonide formulations

\begin{tabular}{|c|c|c|c|c|c|c|}
\hline \multirow[t]{2}{*}{ Percent inhibition } & \multicolumn{3}{|c|}{ Pulmicort Respules ${ }^{\circledR}$} & \multicolumn{3}{|l|}{ BUD-SSMs } \\
\hline & $\begin{array}{l}\text { I hour before } \\
\text { challenge }\end{array}$ & $\begin{array}{l}\text { I } 2 \text { hours before } \\
\text { challenge }\end{array}$ & $\begin{array}{l}23 \text { hours before } \\
\text { challenge }\end{array}$ & $\begin{array}{l}\text { I hour before } \\
\text { challenge }\end{array}$ & $\begin{array}{l}\text { I } 2 \text { hours before } \\
\text { challenge }\end{array}$ & $\begin{array}{l}23 \text { hours before } \\
\text { challenge }\end{array}$ \\
\hline Total cell counts & $84.66 \pm 2.96$ & $83.80 \pm 5.54$ & $25.06 \pm 6.91$ & $66.75 \pm 5.18$ & $91.90 \pm 3.76$ & $76.94 \pm 5.11$ \\
\hline Eosinophil counts & $97.07 \pm 7.94$ & $81.33 \pm 6.84$ & $38.93 \pm 10.43$ & $72.26 \pm 8.87$ & $99.93 \pm 4.84$ & $96.41 \pm 4.52$ \\
\hline Neutrophil counts & $72.38 \pm 8.83$ & $49.41 \pm 8.50$ & $13.92 \pm 5.30$ & $46.18 \pm 7.44$ & $76.80 \pm 3.34$ & $64.44 \pm 6.08$ \\
\hline Lymphocyte counts & $64.69 \pm 12.92$ & $37.53 \pm 4.45$ & $55.56 \pm 17.53$ & $62.88 \pm 11.80$ & $79.26 \pm 9.37$ & $58.52 \pm 17.85$ \\
\hline Macrophage counts & $88.67 \pm 5.77$ & $59.42 \pm 8.79$ & $21.24 \pm 11.70$ & $81.55 \pm 5.81$ & $96.77 \pm 4.86$ & $66.27 \pm 8.27$ \\
\hline
\end{tabular}

Abbreviation: BUD-SSMs, PEG $_{5000}$-DSPE polymeric micelles containing budesonide.

and consequently showing a prolonged duration of action, compared with other inhaled steroids..$^{30,65}$ Treatment with BUD-SSMs led to an extreme and prolonged $(P<0.05)$ inhibitory effect compared with Pulmicort Respules ${ }^{\circledR}$ at 12 and 24 hours before challenge (Table 3). It should be noted that the antigen-induced cell infiltration in the airways was not affected by the placebo formulation $\left(\mathrm{PEG}_{5000}-\mathrm{DSPE}\right)$, which was similarly prepared by coprecipitation and reconstitution, and administered as a rehydrated powder ready for aerosolization, demonstrating that the polymer had no inhibitory effect in this animal model (data not shown).

Because budesonide undergoes extensive hepatic inactivation (first-pass metabolism) by virtue of its molecular design, with a half-life of about 2.8 hours, it is likely that this inhibitory effect (Figure 7) resulted from the local effect of budesonide in the lung. ${ }^{66}$ In addition, pulmonary absorption differs considerably due to the physicochemical properties of the drug, such as solubility ${ }^{67,68}$ After particles deposit on the surface of the airways, they are wetted and dissolve in the airway lining fluid. Inhaled drug particles with low solubility (such as budesonide in Pulmicort Respules ${ }^{\circledR}$ ) take a substantial period of time for solubilization and partitioning between the phases of the airway lining, and are preferentially cleared from the airways by mucociliary transport and phagocytosis. Inhaled drug particles with high solubility (such as budesonide in SSMs) enter into and dissolve in the airway lining fluid more rapidly, and are therefore less susceptible to mucociliary clearance. ${ }^{69-71}$ Therefore, the microsuspension (Pulmicort Respules ${ }^{\circledR}$ ) is transported out of the lungs via cilia, whereas nanoparticles can adhere onto the mucosal surface for a longer period and in that way increase the residence time of the drug in the lung. ${ }^{72}$ Existing pharmacokinetic-pharmacodynamic studies have demonstrated that the pulmonary residence time of inhaled glucocorticoids defines their anti-inflammatory action in the lung, providing the opportunity for sustained-release formulations to be beneficial. ${ }^{73} \mathrm{~A}$ recent pharmacokinetic study of paclitaxel $+\mathrm{PEG}_{5000}-\mathrm{DSPE}$ found a significantly higher area under the curve for paclitaxel in rat lung with a low systemic concentration (plasma, liver, and spleen) compared with its area under the curve following intravenous administration due to the localization of chemotherapy to the lungs, which in turn avoids unwanted side effects. The same study found that paclitaxel $+\mathrm{PEG}_{5000}-\mathrm{DSPE}$ produced similar drug levels to that of paclitaxel in the first hour after intratracheal inhalation, but that higher paclitaxel concentrations were found in the lungs at 12 hours compared with paclitaxel at the same time. ${ }^{37}$ These results confirmed the impact of SSMs as sustained-release formulations, from which budesonide is slowly released over time. As a result, BUD-SSMs inhibited airway inflammation in the asthma/chronic obstructive pulmonary disease model more effectively than the commercial dosage form. The SSM system for budesonide would help to prevent the side effects associated with systemic exposure to budesonide by decreasing the dose due to the prolonged duration of action. The new BUD-SSM system might thus be beneficial as a treatment for asthma, chronic obstructive pulmonary disease, and other inflammatory airway diseases.

\section{Conclusion}

We successfully incorporated budesonide into SSMs of the PEGylated polymer, PEG $_{5000}$-DSPE, with appropriate physicochemical properties. The in vitro release studies indicated the sustained-release potential of BUD-SSMs. Furthermore, the BUD-SSMs showed superior aerodynamic characteristics compared with Pulmicort Respules ${ }^{\circledR}$, being fine enough to be inhaled and reach into the deep lung tissue. The pharmacodynamic study showed a significantly longer duration of inhibition of inflammatory cell infiltration in the airways of antigen-induced asthmatic rats which was prolonged for up to 24 hours, compared with Pulmicort Respules ${ }^{\circledR}$. In general, the SSM system has the ability to keep budesonide at or near the desired pharmacological site of action and to provide selective and prolonged activity in the lung, thereby reducing systemic toxicity. Overall, the in vitro and in vivo studies of BUD-SSMs resulted in a good understanding of the potential use of SSMs as a pulmonary delivery system. 


\section{Acknowledgments}

This work was supported by a grant from the Universiti Sains Malaysia (RU Grant 815001). MNS and SAM gratefully acknowledge the Universiti Sains Malaysia for granting them a postgraduate student fellowship to help fund this research.

\section{Disclosure}

The authors report no conflicts of interest in this work.

\section{References}

1. Zaru M, Mourtas S, Klepetsanis P, Fadda AM, Antimisiaris SG. Liposomes for drug delivery to the lungs by nebulization. Eur J Pharm Biopharm. 2007;67(3):655-666.

2. Jaspart S, Bertholet P, Piel G, Dogne JM, Delattre L, Evrard B. Solid lipid microparticles as a sustained release system for pulmonary drug delivery. Eur J Pharm Biopharm. 2007;65(1):47-56.

3. Bailey MM, Berkland CJ. Nanoparticle formulations in pulmonary drug delivery. Med Res Rev. 2009;29(1):196-212.

4. Cook RO, Pannu RK, Kellaway IW. Novel sustained release microspheres for pulmonary drug delivery. J Control Release. 2005;104(1): 79-90.

5. Fu J, Fiegel J, Krauland E, Hanes J. New polymeric carriers for controlled drug delivery following inhalation or injection. Biomaterials. 2002;23(22):4425-4433.

6. Grenha A, Grainger CI, Dailey LA, et al. Chitosan nanoparticles are compatible with respiratory epithelial cells in vitro. Eur J Pharm Sci. 2007;31(2):73-84.

7. Smola M, Vandamme T, Sokolowski A. Nanocarriers as pulmonary drug delivery systems to treat and to diagnose respiratory and non respiratory diseases. Int J Nanomedicine. 2008;3(1):1-19.

8. El-Sherbiny IM, Smyth HDC. Biodegradable nano-micro carrier systems for sustained pulmonary drug delivery: (I) self-assembled nanoparticles encapsulated in respirable/swellable semi-IPN microspheres. Int J Pharm. 2010;395(1-2):132-141.

9. Grenha A, Seijo B, Remunan-Lopez C. Microencapsulated chitosan nanoparticles for lung protein delivery. Eur J Pharm Sci. 2005;25(4-5): 427-437.

10. Gaucher G, Dufresne MH, Sant VP, Kang N, Maysinger D, Leroux JC. Block copolymer micelles: preparation, characterization and application in drug delivery. J Control Release. 2005;109(1-3):169-188.

11. Mikhail AS, Allen C. Block copolymer micelles for delivery of cancer therapy: transport at the whole body, tissue and cellular levels. J Control Release. 2009;138(3):214-223.

12. Riess G. Micellization of block copolymers. Prog Polym Sci. 2003; 28(7):1107-1170.

13. Gao Z, Lukyanov AN, Singhal A, Torchilin VP. Diacyllipid-Polymer Micelles as Nanocarriers for Poorly Soluble Anticancer Drugs. Nano Lett. 2002;2(9):979-982.

14. Torchilin VP. Structure and design of polymeric surfactant-based drug delivery systems. J Control Release. 2001;73(2-3):137-172.

15. Jones MC, Leroux JC. Polymeric micelles - a new generation of colloidal drug carriers. Eur J Pharm Biopharm. 1999;48(2):101-111.

16. Sezgin Z, Yüksel N, Baykara T. Preparation and characterization of polymeric micelles for solubilization of poorly soluble anticancer drugs. Eur J Pharm Biopharm. 2006;64(3):261-268.

17. Lim SB, Rubinstein I, Önyüksel H. Freeze drying of peptide drugs self-associated with long-circulating, biocompatible and biodegradable sterically stabilized phospholipid nanomicelles. Int J Pharm. 2008; 356(1-2):345-350.

18. Smola M, Vandamme T, Sokolowski A. Nanocarriers as pulmonary drug delivery systems to treat and to diagnose respiratory and non respiratory diseases. Int J Nanomedicine. 2008;3(1):1-19.
19. Vermehren C, Jørgensen K, Schiffelers R, Frokjaer S. Activity of mammalian secreted phospholipase A(2) from inflammatory peritoneal fluid towards PEG-liposomes. Early indications. Int J Pharm. 2001; 214(1-2):93-98.

20. Koo OM, Rubinstein I, Onyuksel H. Camptothecin in sterically stabilized phospholipid micelles: a novel nanomedicine. Nanomedicine. 2005;1(1):77-84.

21. Cesur H, Rubinstein I, Pai A, Önyüksel H. Self-associated indisulam in phospholipid-based nanomicelles: a potential nanomedicine for cancer. Nanomedicine. 2009;5(2):178-183.

22. Zhang L, Hu Y, Jiang X, Yang C, Lu W, Yang YH. Camptothecin derivative-loaded poly(caprolactone-co-lactide)-b-PEG-b-poly(caprolactoneco-lactide) nanoparticles and their biodistribution in mice. $J$ Control Release. 2004;96(1):135-148

23. Sahib MN, Darwis Y, Khiang PK, Tan YTF. Aerodynamic characterization of marketed inhaler dosage forms: High performance liquid chromatography assay method for the determination of budesonide. Afr J Pharm Pharmacol. 2010;4(12):878-884.

24. Davies NM, Feddah MR. A novel method for assessing dissolution of aerosol inhaler products. Int J Pharm. 2003;255(1-2):175-187.

25. Zhang Y, Huo M, Zhou J, et al. DDSolver: an add-in program for modeling and comparison of drug dissolution profiles. AAPS J. 2010;12(3): 263-271.

26. Costa FO, Sousa JJ, Pais AA, Formosinho SJ. Comparison of dissolution profiles of ibuprofen pellets. J Control Release. 2003;89(2):199-212.

27. Sahib MN, Darwis Y, Khiang PK, Fung Tan YT. Aerodynamic characterization of beclomethasone dipropionate from beclate-50 inhaler ${ }^{\circledR}$ by HPLC-UV. J Liq Chromatogr Relat Technol. 2011;34(8):613-621.

28. Wiggins NA. The Development of a Mathematical Approximation Technique to Determine the Mass Median Aerodynamic Diameter (MMAD) and Geometric Standard Deviation (GSD) of Drug Particles in an Inhalation Aerosol Sprat. Drug Dev Ind Pharm. 1991;17(14): 1971-1986.

29. Yamamoto H, Kuno Y, Sugimoto S, Takeuchi H, Kawashima Y. Surface-modified PLGA nanosphere with chitosan improved pulmonary delivery of calcitonin by mucoadhesion and opening of the intercellular tight junctions. J Control Release. 2005;102(2):373-381.

30. Onoue S, Sato H, Kawabata Y, Mizumoto T, Hashimoto N, Yamada S. In vitro and in vivo characterization on amorphous solid dispersion of cyclosporine A for inhalation therapy. J Control Release. 2009;138(1): 16-23.

31. Green C, Knight J, Precious S, Simpkin S. Ketamine alone and combined with diazepam or xylazine in laboratory animals: a 10 year experience. Lab Anim. 1981;15(2):163-170.

32. Andersson SE, Zackrisson C, Behrens K, et al. Effect of allergen provocation on inflammatory cell profile and endothelin-like immunoreactivity in guinea-pig airways. Allergy. 1995;50(4):349-358.

33. Sakagami M, Kinoshita W, Sakon K, Sato J, Makino Y. Mucoadhesive beclomethasone microspheres for powder inhalation: their pharmacokinetics and pharmacodynamics evaluation. J Control Release. 2002; 80(1-3):207-218.

34. Zhang JX, Hansen CB, Allen TM, Boey A, Boch R. Lipid-derivatized poly(ethylene glycol) micellar formulations of benzoporphyrin derivatives. J Control Release. 2003;86(2-3):323-338.

35. Rijcken CJ, Soga O, Hennink WE, Nostrum CF. Triggered destabilisation of polymeric micelles and vesicles by changing polymers polarity: an attractive tool for drug delivery. J Control Release. 2007;120(3): 131-148.

36. Yang W, Peters JI, Williams III RO. Inhaled nanoparticles - a current review. Int J Pharm. 2008;356(1-2):239-247.

37. Gill KK, Nazzal S, Kaddoumi A. Paclitaxel loaded PEG ${ }_{5000}-$ DSPE micelles as pulmonary delivery platform: Formulation characterization, tissue distribution, plasma pharmacokinetics, and toxicological evaluation. Eur J Pharm Biopharm. May 7, 2011;79(2):276-284.

38. Fidler IJ, Raz A, Fogler WE, Kirsh R, Bugelski P, Poste G. Design of liposomes to improve delivery of macrophage-augmenting agents to alveolar macrophages. Cancer Res. 1980;40(12):4460-4466. 
39. Zhang JX, Li XJ, Qiu LY, et al. Indomethacin-loaded polymeric nanocarriers based on amphiphilic polyphosphazenes with poly (N-isopropylacrylamide) and ethyl tryptophan as side groups: Preparation, in vitro and in vivo evaluation. $J$ Control Release. 2006;116(3): 322-329.

40. Aliabadi HM, Elhasi S, Mahmud A, Gulamhusein R, Mahdipoor P, Lavasanifar A. Encapsulation of hydrophobic drugs in polymeric micelles through co-solvent evaporation: The effect of solvent composition on micellar properties and drug loading. Int J Pharm. 2007; 329(1-2):158-165.

41. Mu L, Feng SS. Fabrication, characterization and in vitro release of paclitaxel (Taxol) loaded poly (lactic-co-glycolic acid) microspheres prepared by spray drying technique with lipid/cholesterol emulsifiers. J Control Release. 2001;76(3):239-254.

42. Arias MJ, Moyano JR, Ginés JM. Study by DSC and HSM of the oxazepam-PEG 6000 and oxazepam-D-mannitol systems: Application to the preparation of solid dispersions. Thermochim Acta. 1998;321(1-2): 33-41.

43. Zhang X, Jackson JK, Burt HM. Development of amphiphilic diblock copolymers as micellar carriers of taxol. Int J Pharm. 1996;132(1-2): 195-206.

44. Ali HR, Edwards HG, Kendrick J, Munshi T, Scowen IJ. Vibrational spectroscopic study of budesonide. J Raman Spectrosc. 2007;38(7): 903-908.

45. Tajber L, Corrigan DO, Corrigan OI, Healy AM. Spray drying of budesonide, formoterol fumarate and their composites - I. Physicochemical characterisation. Int J Pharm. 2009;367(1-2):79-85.

46. Falamarzian A, Lavasanifar A. Optimization of the hydrophobic domain in poly(ethylene oxide)-poly([var epsilon]-caprolactone) based nanocarriers for the solubilization and delivery of Amphotericin B. Colloids Surf B Biointerfaces. 2010;81(1):313-320.

47. Muthu M, Singh S. Poly (D, L-Lactide) nanosuspensions of risperidone for parenteral delivery: formulation and in-vitro evaluation. Curr Drug Deliv. 2009;6(1):62-68

48. Costa P, Sousa Lobo JM. Modeling and comparison of dissolution profiles. Eur J Pharm Sci. 2001;13(2):123-133.

49. Dash S, Murthy PN, Nath L, Chowdhury P. Kinetic modeling on drug release from controlled drug delivery systems. Acta Pol Pharm. 2010; 67(3):217-223.

50. Derakhshandeh K, Soheili M, Dadashzadeh S, Saghiri R. Preparation and in vitro characterization of 9-nitrocamptothecin-loaded long circulating nanoparticles for delivery in cancer patients. Int J Nanomedicine. 2010;5:463-471.

51. Abdulla JM, Tan YT, Darwis Y. Rehydrated lyophilized rifampicin-loaded mPEG-DSPE formulations for nebulization. AAPS Pharm Sci Tech. 2010;11(2):663-671.

52. Field AP. Discovering statistics using SPSS: (and sex and drugs and rock ' $n$ ' roll). 3rd ed. London, UK: SAGE publications Ltd; 2009.

53. Yuksel N, Kanik AE, Baykara T. Comparison of in vitro dissolution profiles by ANOVA-based, model-dependent and -independent methods. Int J Pharm. 2000;209(1-2):57-67.

54. Chow SC, Ki FY. Statistical comparison between dissolution profiles of drug products. J Biopharm Stat. 1997;7(2):241-258.

55. Polli JE, Rekhi GS, Augsburger LL, Shah VP. Methods to compare dissolution profiles and a rationale for wide dissolution specifications for metoprolol tartrate tablets. J Pharm Sci. 1997;86(6): 690-700.

International Journal of Nanomedicine

\section{Publish your work in this journal}

The International Journal of Nanomedicine is an international, peerreviewed journal focusing on the application of nanotechnology in diagnostics, therapeutics, and drug delivery systems throughout the biomedical field. This journal is indexed on PubMed Central, MedLine, CAS, SciSearch ${ }^{\circledR}$, Current Contents ${ }^{\circledR} /$ Clinical Medicine,
56. Gonjari ID, Karmarkar AB, Hosmani A. Evaluation of in vitro dissolution profile comparison methods of sustained release tramadol hydrochloride liquisolid compact formulations with marketed sustained release tablets. Digest J Nanomaterials Biostructures. 2009;4:651-661.

57. Adams E, Coomans D, Smeyers-Verbeke J, Massart DL. Application of linear mixed effects models to the evaluation of dissolution profiles. Int J Pharm. 2001;226(1-2):107-125.

58. O'Hara T, Dunne A, Butler J, Devane J. A review of methods used to compare dissolution profile data. Pharm Sci and Technolo Today. 1998; 1(5):214-223.

59. Vaghi A, Berg E, Liljedahl S, Svensson JO. In vitro comparison of nebulised budesonide (Pulmicort Respules ${ }^{\circledR}$ ) and beclomethasone dipropionate (Clenil ${ }^{\circledR}$ per Aerosol). Pulm Pharmacol Ther. 2005;18(2): $151-153$.

60. Ostrander KD, Bosch HW, Bondanza DM. An in-vitro assessment of a NanoCrystal beclomethasone dipropionate colloidal dispersion via ultrasonic nebulization. Eur J Pharm Biopharm. 1999;48(3):207-215.

61. Dailey LA, Schmehl T, Gessler T, et al. Nebulization of biodegradable nanoparticles: impact of nebulizer technology and nanoparticle characteristics on aerosol features. J Control Release. 2003;86(1):131-144.

62. Coombes AG, Tasker S, Lindblad M, et al. Biodegradable polymeric microparticles for drug delivery and vaccine formulation: the surface attachment of hydrophilic species using the concept of poly(ethylene glycol) anchoring segments. Biomaterials. 1997;18(17):1153-1161.

63. Mitchell J, Newman S, Chan HK. In vitro and in vivo aspects of cascade impactor tests and inhaler performance: a review. AAPS Pharm Sci Tech. 2007;8(4):E110

64. Dawkins PA, Stockley RA. Animal models of chronic obstructive pulmonary disease. Thorax. 2001;56(12):972-977.

65. Leung SY, Williams AS, Nath P, et al. Dose-dependent inhibition of allergic inflammation and bronchial hyperresponsiveness by budesonide in ovalbumin-sensitised Brown-Norway rats. Pulm Pharmacol Ther. 2008;21(1):98-104.

66. Miller-Larsson A, Jansson P, Runstrom A, Brattsand R. Prolonged airway activity and improved selectivity of budesonide possibly due to esterification. Am J Respir Crit Care Med. 2000;162(4 Pt 1):1455-1461.

67. Tronde A, Nordén B, Marchner H, Wendel AK, Lennernäs H, Bengtsson UH. Pulmonary absorption rate and bioavailability of drugs in vivo in rats: structure-absorption relationships and physicochemical profiling of inhaled drugs. J Pharm Sci. 2003;92(6):1216-1233.

68. Tronde A, Nordén B, Jeppsson AB, et al. Drug absorption from the isolated perfused rat lung-correlations with drug physicochemical properties and epithelial permeability. J Drug Target. 2003;11(1):61-74.

69. Geiser M, Gerber P, Maye I, Im Hof V, Gehr P. Retention of Teflon particles in hamster lungs: a stereological study. J Aerosol Med. 2000; 13(1):43-55.

70. John J, Wollmer P, Dahlback M, Luts A, Jonson B. Tidal volume and alveolar clearance of insoluble particles. J Appl Physiol. 1994;76(2): 584-588.

71. Lay JC, Stang MR, Fisher PE, Yankaskas JR, Bennett WD. Airway retention of materials of different solubility following local intrabronchial deposition in dogs. J Aerosol Med. 2003;16(2):153-166.

72. Jacobs C, Müller RH. Production and characterization of a budesonide nanosuspension for pulmonary administration. Pharm Res. 2002;19(2): 189-194.

73. Cerasoli F Jr. Developing the ideal inhaled corticosteroid. Chest. 2006; 130(1 Suppl):54S-64S.

\section{Dovepress}

Journal Citation Reports/Science Edition, EMBase, Scopus and the Elsevier Bibliographic databases. The manuscript management system is completely online and includes a very quick and fair peer-review system, which is all easy to use. Visit http://www.dovepress.com/ testimonials.php to read real quotes from published authors. 